\title{
Modeling and Performance Simulation of a Retail Store as a Smart Grid Ready Building
}

\author{
Muhyiddine Jradi, Henrik Engelbrecht Foldager, \\ Rasmus Camillus Jeppesen, Jakob Hviid, \\ Mikkel Ask Rasmussen, Mikkel Baun Kjærgaard \\ Mærsk Mc-Kinney Møller Institute \\ University of Southern Denmark, \\ Odense, Denmark
}

\begin{abstract}
The increasing distributed generation of renewable energy and alternative energy generation technologies is making it important to consider when and how buildings consume energy from a cost and sustainability perspective. If buildings can be flexible in their consumption patterns they can use the greenest and most efficient produced energy and help solve gridside imbalances with cost benefits. Building modeling and simulation can provide an effective method for evaluating flexibility opportunities in buildings. However, most building loads depend on the occupant presence and dynamic interactions between different building components. Therefore, occupant presence and different interactions have to be taken into account when developing the energy performance model and when evaluating the simulation results for flexibility. In particular, this is key in the retail sector which this paper considers as the case. In this paper we present a detailed simulation model of a supermarket, evaluate different flexibility scenarios and discuss the flexibility results in light of an ethnographic study of the work processes and the store operation.
\end{abstract}

\section{Introduction}

The increasing distributed generation of green electricity is making it important to reconsider when buildings consume energy to secure supply stability. If buildings can be flexible in their consumption patterns they can help: 1) solve grid-side imbalances with cost benefits for building owners and 2) increase the use of the greenest produced electricity. Retail stores use a considerable amount of electricity as mentioned by Mylona et al. (2017). Therefore, this type of building is relevant to consider for providing demandside energy flexibility services as argued by Piette et al. (2014). However, existing work on demandside flexibility has only considered narrow aspects of the loads and opportunities in retail buildings, e.g., Shafiei et al. (2013). Previous work has so far created an overview of the loads and practices in different types of retail stores, as well as an estimated flexi- bility potential as provided by Hviid and Kjærgaard (2018). This work highlights the flexibility potential of store loads including lighting, refrigeration, space heating and cooling, ventilation, and ovens. Some of the notable requirements, potential challenges, and barriers to realizing the flexibility potential are the current state of the controllable devices in stores and the limitations in the relationship between work processes and electricity use.

While energy flexibility of public and private buildings has been investigated heavily in the recent years (e.g. Nellemann et al. (2017), Marszal et al. (2017) and Piette et al. (2014)), there are few studies presented aiming to characterize and evaluate energy flexibility of retail stores (e.g. Mylona et al. (2017), Vinther et al. (2016) and Shafiei et al. (2013)). In order to assess and evaluate the energy flexibility potential of an energy efficient retail store, a detailed dynamic energy performance model is needed which is capable of predicting an accurate representation of the store energy usage and indoor environment. A case study of a recently constructed retail store is considered in this study, aiming to assess the impact of various flexibility control strategies on the energy performance of the store. In addition to the dynamic model development, calibration and retail store performance simulation, an anthropological study was carried out in the store including observation and interviews with valuable input to the dynamic model regarding the occupant behavior and activities and occupancy patterns within the retail store. This information is used to inform the simulation model with the actual work processes. Thereby, the model results will provide a basis to suggest and inform about the potential energy flexibility in light of the actual work processes and discuss the potential to change the work processes to improve the energy flexibility level.

Considering the design documents and specifications, an overall dynamic energy performance model was developed in EnergyPlus for the considered Retail store case study. Previous work by Mylona et al. (2017) has presented a study of a retail store with an Ener- 
gyPlus model for the different subsystems and equipment. The study showed that a dynamic energy performance model of the retail store could accurately predict the energy performance with acceptable uncertainty. However, the study did not consider flexibility as a goal. The constructed model of the retail store provides a detailed characterization of the store physical envelope, construction materials, loads, energy systems specifications and layout and store services. The dynamic model was upgraded using information collected about the occupancy patterns in the store and the occupant behavior, through an anthropological analysis carried out over three months. The developed dynamic model was calibrated using heating and electricity monthly consumption data collected from the retail store. The calibrated model was used to simulate the energy performance and the resulting indoor environment in the store.

To evaluate flexibility we build on previous work considering model-based evaluations for other types of buildings (e.g. as presented by Marszal et al. (2017)). We investigate the impact of various energy systems operation strategies and DR events on the store energy performance aiming to evaluate the energy flexibility level. The paper considers two different cases of flexibility in regards to morning and afternoon peaks in consumption following previous work Piette et al. (2014). For each case, it considers the used loads in these hours in regard to food production, ventilation and refrigeration. Based on the results we discuss the challenges of operating the flexibility as part of present work practices.

\section{Methodology}

The methodology to study demand response flexibility in retail stores is illustrated in Figure 1. The methodology can be summarized in eight steps with the dependencies illustrated on the figure. 1) gather technical information for the retail store. 2) gather calibration and validation data. 3) do ethnographic studies of the retail store including observations and interviews to detail the work processes in the store. 4) develop the EnergyPlus model by first creating the 3D model in Google SketchUp and then import the model into OpenStudio to define the building characteristics, such as physical envelope, occupancy, loads, HVAC systems and schedules. 5) define the flexibility scenarios for the evaluation. 6) run simulations using the energy performance model. This includes: model debugging to ensure that the model can simulate without any errors or warnings; conducting model calibration such that the electricity, heating and water consumption match with the actual consumption data from the retail store; Validation with data for one month as the yearly consumption is still not available. 7) evaluate the energy flexibility of the retail store based on the simulation results, which in this instance entails shifting the majority of the elec- tricity consumption from periods of high electricity price to periods of low electricity price. 8) interpret results with regards to the work processes of the store.

\section{Energy Model Development}

The dynamic energy performance model is built following the methodology developed by Jradi et al. (2017) using a holistic approach and considering a package of tools, Google Sketchup, OpenStudio and EnergyPlus. For the model development, detailed drawings that depict the layout of the retail store and design specifications and information from the store on HVAC system, equipment and occupation rates were used. The 3D model is created in Google SketchUp by drawing the retail store ground outline and subsequently divide it into the room distribution as specified in the plans, as illustrated in Figure 2. The different rooms are considered as spaces and must be assigned thermal zones, which is the basis for energy performance and indoor environment calculations. The model used in this study has 23 such thermal zones.

The different building characteristics defined in the model can be separated into four different sections; Constructions, Loads, HVAC system and Operation Schedules. The construction section deals with the physical envelope of the store which is modeled considering the actual envelope design specifications and in accordance with the current building regulation that outlines the maximum allowed U-value for individual building elements. The individual building elements consist of the roof, ceiling, exterior walls, interior walls, floor and fenestrations.

The loads are divided into occupancy presence and activity, interior lighting, electrical equipment and air infiltration loads. All the loads are defined based on their respective maximum capacity and then regulated hourly by fractional schedules. The occupancy is defined by the number of people present whilst the interior lighting is defined as watts per space floor area. The electrical equipment is defined on a detailed level on the basis of the store's inventory list of equipment, machinery and appliances, such that each individual device is modeled separately based on its wattage capacity.

The HVAC system consists of three sub-systems; heating, ventilation and refrigeration. The heating system is supplied by a district heating loop to fulfill the retail store space heating and domestic hot water needs. The district heating system supply and demand sides are modelled and defined. The supply side consists of a series of pumps, a district heating plant and a setpoint manager to regulate the hot water inlet temperature. The demand side consists of a series of baseboard hot water heaters that are placed in the relevant thermal zones, corresponding to the actual radiators in the real store. Similarly, the ventilation sub-systems consist of a supply and demand 


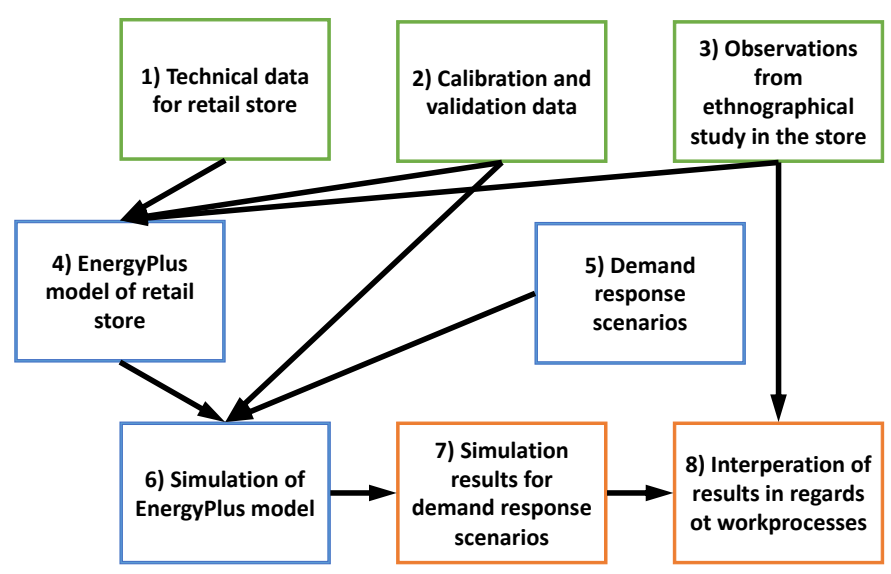

Figure 1: Overview of the methodology of the study.

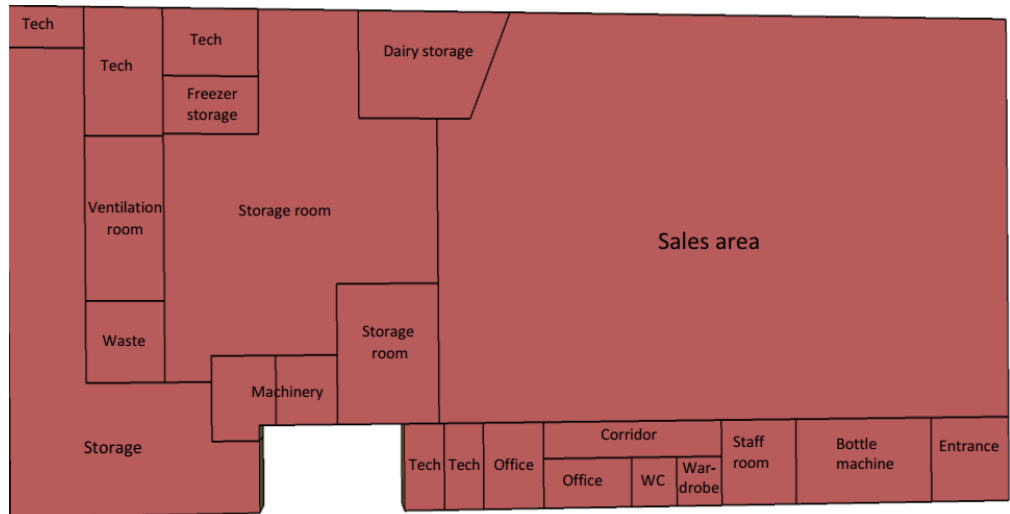

Figure 2: Floor plan of the retail store.

side. The supply side has an outdoor air system, a series of ventilation fans and a setpoint manager to control the air temperature. The demand side is a set of air terminal diffusers that deliver the required air to the relevant thermal zones. There are three ventilation units in total, two of which are equipped with air-to-air heat exchangers. The third HVAC system is majorly used to provide cold air to the two large cold storage rooms in the store.

The refrigeration system serves different units in different positions in the store, using the working fluid R744 to achieve its refrigeration capacity. The system itself is modelled as a main refrigeration condenser unit tied to a compressor running on a transcritical mode of operation. These components are responsible for the refrigeration of 16 display cases in the main sales area and the 2 walk-in cases representing the refrigerated spaces of dairy storage and frozen storage. The walk-in cases are positioned in the store as shown in Figure 2. The thermal cases of these refrigerated units have been defined to comply with the most recent building regulations for cold storage spaces adjoining conditioned areas. In addition, the actual operational setpoints of the display cases in the main sales area and the dairy storage along with the frozen storage spaces are set and defined.

Schedules are defined in the model to manage different loads and equipment operation, where operation controllers were defined to run and control the different energy supply systems. A multitude of schedules are required for the model to ensure a detailed and accurate function, as they define and characterize occupancy, lighting, electrical equipment, indoor temperature and district heating temperatures on an hourly basis. The occupancy schedules are fractional values of maximum number of people present in the retail store, with different schedules for weekdays and weekends, an example of which is shown in Figure 3.

\section{Ethnographic Study of the Retail Store}

The aim of the anthropological study in the retail store was to develop descriptions and representations of work processes which could be used to 1) inform the design of the simulation model, 2) explore how work practices impact the stores energy consumption, and 3) identify opportunities and challenges for energy flexibility considering the work processes in the store. Questions guiding the design and planning of the 


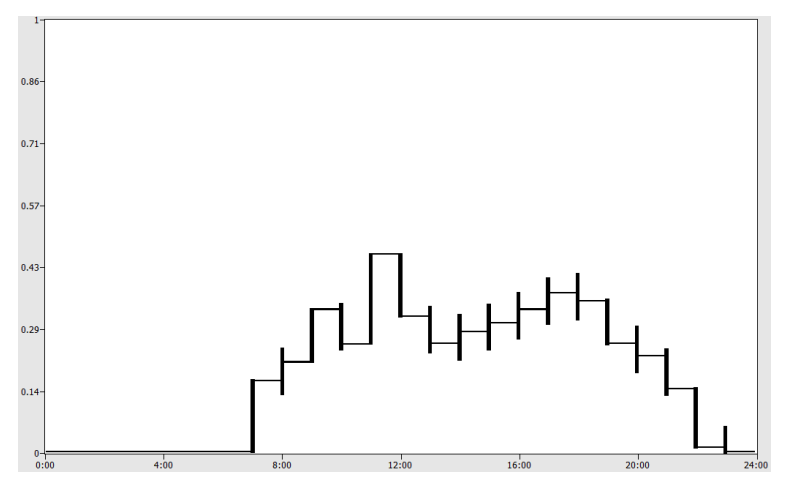

Figure 3: The weekday occupancy schedule derived from the anthropological study.

study included: What does a week in the store look like? What happens in the store during each day of the week? What does the work of managers and employees involve and how is the work organized and carried out?

Our approach in this study of the retail store was inspired by ethnography (or ethnographic field-work) Spradley (1980) and, in particular, the way ethnography (or ethnographic fieldwork) has been developed and applied to understand users and use contexts in the fields of Human-Computer interaction and design Blomberg et al. (2003).

Our research activities involved onsite interviews with the store managers and monitoring employees work, following them around the store as they went through their daily routines, observing their activities and having informal conversations with them about their work and tasks.

Observations of work focused on daily routines and activities such as reception and unpacking of goods (deliveries) and bringing the received goods to the shelves in the shop, production of food and readyprepared dishes in the stores deli, production and sales in the stores baker shop, and the evening routines leading up to closing the shop.

The study involved six visits to the store and approximately 30 hours of observation and interviews in total. All interviews and observations were documented on video for subsequent analysis and evaluation.

In addition to video recordings of interviews and employees carrying out their daily work, our study also allowed gaining access to formal plans and parts of the comprehensive documentation of the store activities. This included the duty roster that shows who is at work during each day of the week, production plans for the deli and baker shop, and tables showing the average turnover and the average number of customers in the shop during each day of the week.

Based on the conducted interviews and observations, a detailed schedule was created characterizing the deliveries of goods throughout the week. Bringing together the duty schedule and what we learned through interviews and observations, tables were developed showing the number of people at work during each day of the week and what routines and activities each group is involved in.

Some of the information collected was directly imported into the energy performance model, for example overview of the number of customers and schedule in the store, while others demanded analysis and processing into new representations of the work due to its qualitative nature. The evaluation and analysis of the information was also included and imported in the energy model to more accurately characterize the occupancy patterns and work processes inside the store.

\section{Energy Supply Systems Operation Strategy}

The store operates mainly based on scheduled electrical devices, ventilation unit and heating system operation patterns. In this section, a more detailed description of the operation strategies of different energy supply systems will be described.

The lighting in the store is handled by a main switch that is activated when the first employee arrives early in the morning. The lights in the main shopping area remain lit until this switch is used again after closing hours. Lights in staff rooms, storage rooms and technical rooms are tied to motion sensors and turn off after a brief duration when no occupants are present.

Ventilation in the store is split into three separate systems; one general and larger system that supplies the main shopping area as well as storage areas, staff rooms and technical rooms. The second smaller system is dedicated specifically to the butcher and delicacy section of the store, and the third system is used as an air cover for the ceiling of the shop. All three systems are uncontrolled by employees and work on a scheduled pattern that activates all three systems at 8 AM and turns them off again at 10 PM on workdays.

The refrigeration system in the store is split between cooling cases for goods in the main shopping area, a cooling storage room for dairy products, and a storage room for frozen goods kept at freezing temperatures. These units operate around the clock to ensure that the wares are not compromised as a result of temperature.

The main portion of the electricity consumption of the store that is not scheduled is electrical equipment usage. The store contains many electrical appliances, and the majority of these are not scheduled, but instead used as needed by the employees and customers, depending on the individual appliance.

Regarding the space heating of the store, all rooms but cold storage are linked to the district heating supply loop, which is set to maintain the indoor temperature between 20 and 23 degrees Celsius during the day depending on the specific setpoints in each section of the retail store. At night during closed hours, 
these heating setpoints are lowered to 15 degrees.

\section{Energy Performance Model Calibration}

The dynamic energy performance model developed for the retail store was calibrated using actual collected data to ensure that the model predicts accurately the energy performance of the retail store with an acceptable uncertainty. Therefore, data on ventilation, lighting, electricity and heating consumption were provided by the parent company of the retail store in order to be used as a basis for the calibration process.

The data received from the retail store include detailed consumption profiles for January, February and September 2018. The monthly predicted consumption of the model has been calibrated to match the data for the respective months, and then expanded to a full year.

The individual electrical systems in the store, such as refrigeration, have been calibrated based on consumption data from the store for September 2018, and then expanded to cover a whole year. The consumption data covers total consumption for the month in hour-by-hour format for all refrigeration as a total, the butcher/delicacy section as a total and unregistered consumption as a total. These values have been used to ensure that the system totals match measured consumption.

In the case of electrical equipment, the consumption schedules in the model have been designed and adjusted to fit these hour-by-hour measurements in order to model the varying operations at different times of the day. Note that this only covers September, and also provides an approximation for human behaviors, as the use of most of the appliances in the butcher/delicacy section is operated entirely by the employees as needed during their working hours. This has been depicted in the model settings as estimated average use schedules. These are based on the provided consumption data and the observed on-site behavior covered in the anthropological section.

As shown in Table 1, the calibrated energy performance model predicts well the electricity and heating consumption of the retail store with an acceptable uncertainty of 0.28 percent and 0.22 percent respectively. This calibrated dynamic energy model will be used as a basis to predict the performance of the retail store as well as investigating various flexibility measures.

Table 1: Model output accuracy - February-March.

\begin{tabular}{lcc}
\hline Consumption & $\begin{array}{c}\text { Electricity } \\
{[\mathrm{MWh}]}\end{array}$ & $\begin{array}{c}\text { Heating } \\
{[\mathrm{GJ}]}\end{array}$ \\
\hline Model & 45.16 & 26.9 \\
Retail store & 44.80 & 27.17 \\
Difference [MWh] & 0.36 & -0.27 \\
Difference [\%] & -0.28 & 0.22 \\
\hline
\end{tabular}

\section{Retail Store Baseline Energy Performance}

Employing the calibrated dynamic energy performance model and considering various specifications, loads, schedules and dynamic interactions, an annual energy simulation was carried out to predict the energy performance of the retail store over a one-year period. As presented in Figure 4, the refrigeration energy consumption is dominating with a contribution of around 48 percent of the overall energy consumption in the store. Heating consumes around 24 percent of the overall consumption with interior electrical equipment having a share of around 14 percent. This shows that in investigating electricity flexibility potential, considering the refrigeration system as well as the electrical equipment operation is a priority. This is also supported in Figure 5, which depicts the annual electricity consumption distribution in the retail store. The three major consumption sections are refrigeration, interior electrical equipment and interior lighting. In addition, Figure 6, provides an overview of the monthly heating consumption numbers in the store with a predicted maximum heating consumption of around $18 \mathrm{MWh}$ in each of January and December months.

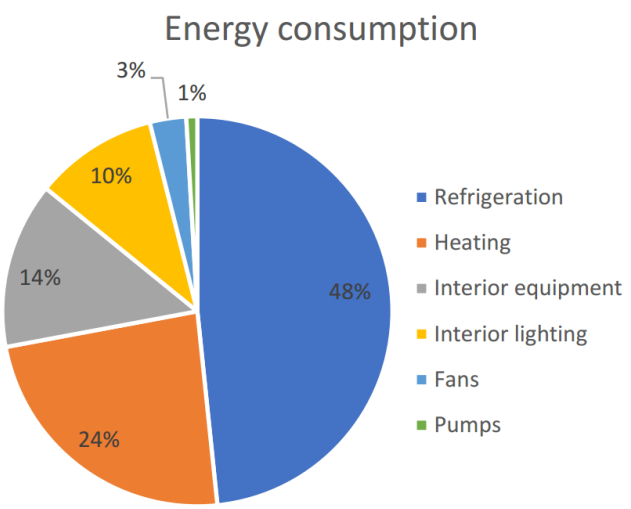

Figure 4: Annual energy consumption distribution.

\section{Electricity distribution}

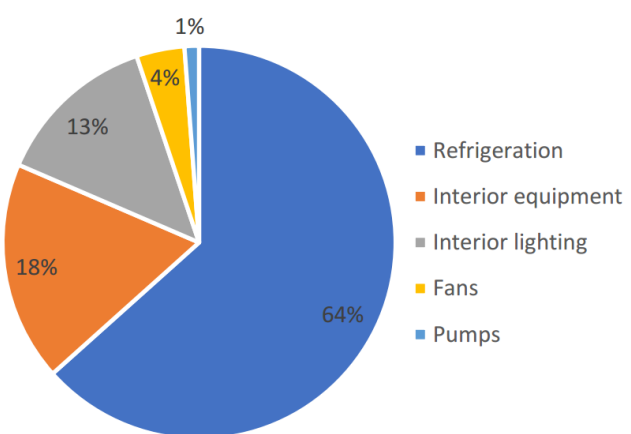

Figure 5: Annual electricity consumption distribution.

\section{Flexibility Scenarios}

In investigating the electrical flexibility potential of the retail store, two periods are considered, 7 AM 
District heating consumption

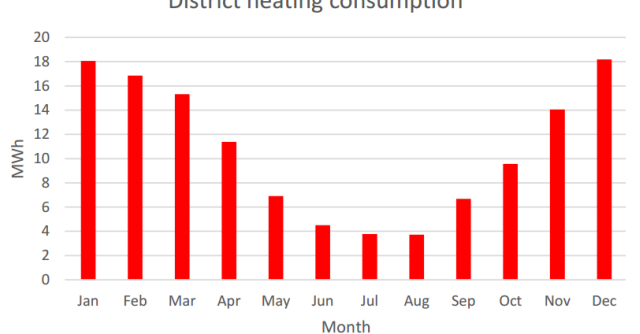

Figure 6: Monthly heating consumption through one year.

to $9 \mathrm{AM}$ and $5 \mathrm{PM}$ to $7 \mathrm{PM}$. These periods have also been considered by previous work on flexibility by Piette et al. (2014). This is implemented by defining and simulating different operation scenarios in the energy performance model, through manipulating the operation schemes, schedules and control algorithms of the targeted systems and equipment. This procedure is inspired by method proposed by Marszal et al. (2017). The electrical consumption of affected systems is thereby shifted or lowered to account for peak-load hours, and should amount to a lesser total consumption in these hours.

The flexibility scenarios cover three major approaches, the first of which is reducing electric equipment consumption in the peak-hour period of $7 \mathrm{AM}$ to $9 \mathrm{AM}$ and doing the same for the period of $5 \mathrm{PM}$ to 7 PM. This equipment covers appliances such as ovens, food appliances, disposal systems for bottles and used cardboard, and similar equipment that could be in use at other times outside of peak-load hours without compromising day-to-day operation. The way this is modelled is to change the fractional schedules that control the different appliances. A fractional schedule value of 1 means that an appliance is running at peak load during that duration, and 0 indicates that the appliance is shut down. Scenario 1, $7 \mathrm{AM}$ to $9 \mathrm{AM}$, is modelled on the assumption of shifting the deli production and cleanup duties, whereby certain equipment is either reduced, shut down or left at normal operating levels. Scenario 1, $5 \mathrm{PM}$ to 7 $\mathrm{PM}$, is based on reduced work assignments, which again is modelled by either reducing, shutting down or maintaining normal operation for different equipment. For instance, if the store oven operation is reduced, it could be by changing the schedule from 0.2 to 0.1 . If it is shut down, it is changed to 0 , and normal would indicate no changes. From 7 AM to 9 $\mathrm{AM}$, all equipment is shutdown, save the baker disk, store oven, cash register and bottle machine, which are either reduced or slightly reduced. From 5 PM to 7 PM, everything but the staff PC's and bottle machine is shutdown, while the cash registers operates at normal capacity. To summarize, the main difference in the two periods is that all the equipment is operating in the morning, but not in the evening, as the deli and butcher devices cease work from 2 PM.
The second approach is to reduce ventilation energy consumption in the peak-load hours. This is done by adjusting the control schedules in the model for the three separate ventilation systems to shut off during these hours. As this will naturally affect the indoor climate in terms of temperature, the output of the model has been inspected to ensure that shutting off the ventilation system will not violate the indoor thermal comfort. This is shown later in Figure 7.

The third approach in investigating flexibility is to lower the electricity consumption of refrigeration units. This is done by simulating a pre-cooling method, where the setpoint of the refrigeration units is reduced to allow higher capacity in the hour preceding the peak-load hours, and subsequently increasing the units setpoint in the peak hours to reduce the capacity used. In the model, this is done by changing the control schedules and setpoints accordingly to affect an increase followed by a longer and greater decrease with parameter chosen based on Vinther et al. (2016). Obviously, a predicted increase in the refrigeration consumption in the hour where the setpoint is reduced, however, in the two peak hours, the consumption of the refrigeration system is predicted to decrease substantially due to the lower capacity used in these hours.

Previous work by Piette et al. (2014) has also considered dimming lights as a flexibility option. Lights were not included in the simulations due to the store owner rejecting this idea as they had lux standards that they had to keep.

\section{Flexibility Investigation Results}

Table 2 and 3 show the simulation results for implementing the first flexibility approach on the electrical equipment. It is shown that implementing this measure will allow savings around $5.6 \mathrm{~kW}$ and $2.94 \mathrm{~kW}$ on the equipment capacity in the two periods of 7 and $9 \mathrm{AM}$ and 17 and $19 \mathrm{PM}$, respectively. In addition, Table 4 shows that a ventilation system capacity of around $1.65 \mathrm{kWh}$ could be saved by implementing the second flexibility measure targeting the ventilation system operation. Moreover, Figure 6 shows the impact of implementing the ventilation flexibility measure on the temperature profile in the main hall in the retail store. As shown in the figure, turning off the ventilation in the evening period will lead to an increase in the temperature in the store, however the increase is limited to less than 2 degrees Celsius. This confirms that this flexibility measure could save on the used capacity of the ventilation system, without violating the indoor thermal comfort standards. Finally, Table 5 shows the impact of implementing the third flexibility approach targeting the refrigeration system. Based on the simulations, this approach will lead to an increase in the required refrigeration capacity of around $15.1 \mathrm{~kW}$ in the pre-cooling hour and to a substantial reduction of $20.8 \mathrm{~kW}$ on the re- 
frigeration capacity needed in the store in the two considered flexibility periods. A short coming of the EnergyPlus model is that it does not model the refrigeration differences accurately throughout the day. Therefore, the morning and evening results are similar.

Table 2: Equipment flexibility 7-9.

\begin{tabular}{ll}
\hline Annual Partial consumption - Equipment \\
\hline Base model & $51.32 \mathrm{MWh}$ \\
Flex model & $47.21 \mathrm{MWh}$ \\
$\mathrm{kW}$ per flex hour & 5.63 \\
\hline
\end{tabular}

Table 3: Equipment flexibility 17-19.

\begin{tabular}{ll} 
Annual Partial consumption - Equipment \\
\hline Base model & $51.32 \mathrm{MWh}$ \\
Flex model & $49.17 \mathrm{MWh}$ \\
$\mathrm{kW}$ per flex hour & 2.94 \\
\hline
\end{tabular}

Table 4: Ventilation flexibility.

\begin{tabular}{ll}
\hline Annual Partial consumption - Ventilation \\
\hline Base model & $11.23 \mathrm{MWh}$ \\
Flex model & $8.82 \mathrm{MWh}$ \\
$\mathrm{kW}$ per flex hour & 1.65 \\
\hline
\end{tabular}

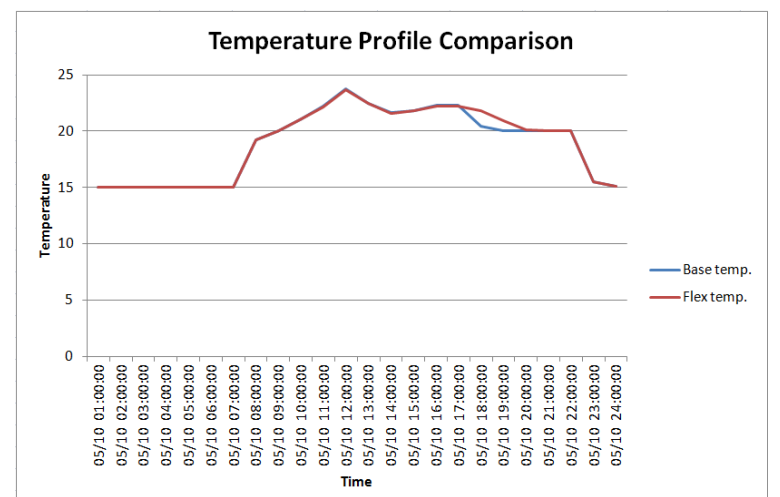

Figure 7: Temperature profiles with and without flexible ventilation.

Table 5: Refrigeration flexibility 7-9 and 17-19.

Daily Partial consumption - Refrigeration

Base model $475.5 \mathrm{kWh}$

Flex model (pre-cooling) 6-7 and 16-17 $505.7 \mathrm{kWh}$ $\mathrm{kWh}$ Increase per flex hour

Flex model (flexibility) 7-9 and 17-19 $392.3 \mathrm{kWh}$ kWh Decrease per flex hour 20.8

\section{Discussion}

As described above, the flexibility scenarios involve turning off or changing operation patterns of electri- cal equipment to shift the electricity consumption. The triggered electrical equipment in our flexibility scenarios include the electrical production equipment in the stores deli, electrical equipment in the baker shop, selected cash registers, office PCs, the cardboard baler that is used to compact or compress cardboard waste, and the vending machine where customers can return used bottles (as part of the Danish deposit system). One of the consequences of taking electrical equipment out of operation is that the activities that involve use of this equipment cannot be carried out. Therefore, it is important to consider what are the implications of turning off equipment on customers and employees including work processes and shopping behavior.

Here are a few examples of how the adjustments made might affect work processes and shopping behaviour.

Both flexibility scenarios involve taking the electrical production equipment in the stores deli out of operation (from 7:00-9:00 and 17:00-19:00, respectively). An consequence of this adjustment would be that the deli cannot produce the food and ready-prepared dishes that involve the electrical equipment that has been taken out of operation. Food items and dishes that involve use of the delis electrical equipment include meatballs, deep-fried fillets of fish, lasagna, various stews etc. The way work is organised today, production of food and ready-prepared dishes in the stores deli take place in the morning (from 6:00 to 10:00 and from 6:00 to 14:00 on other days). Thus, taking the production equipment out of operation at 7:00-9:00, as one of the flexibility scenarios suggest, would interfere with how work is organised today and might involve either cancelling the production or moving the production to another point in time. This, in turn, might affect the employees involved in the delis production and have an impact on when food and dishes from the stores deli are ready for sale. How the implications of taking the delis production equipment out of operation will affect the employees involved in the delis production will depend on how the store chooses to deal with the situation.

Both flexibility scenarios also involve taking the cardboard baler that is used to compress cardboard waste out of operation. As with the delis production equipment, taking the baler out of operation in the morning seems to have greater implications for work than taking the baler out of operation in late afternoon and early evening. The store receives fresh supplies of items for sale every day. The supplies are delivered in the morning. Goods are delivered in parcels and cardboard boxes, which in turn are packed on pallets. Upon delivery the pallets are unpacked in the stores main storage. Parcels and boxes are placed on carts. And the carts are taken to the shop where parcels and boxes are unpacked and the goods placed on the shelves. Upon delivery the pallets are unpacked in 
the stores main storage, parcels and boxes are places on carts, and the carts are taken to the shop where parcels and boxes are unpacked and the goods are placed on the stores shelves ready for sale. Taking the baler out of operation in the morning would, thus, conflict with the daily routine of receiving and unpacking deliveries and bringing goods to the shelves of the shop. Taking the baler out of operation during this morning routine would mean that the cardboard waste cannot be immediately compressed.

For the baker shop, taking the grill in the baker shop out of operation would mean that the shop cannot offer grilled sandwiches during the time the grill is out of operation. Turning off the oven in the baker shop would mean that the baker shop cannot produce pizza and sausage rolls which, in turn, will affect when the baker shop can offer customers these products for sale.

For other equipment taking cash registers out of operation will reduce the number of operational cash registers. Taking office PCs out of operation would mean that activities involving use of office PCs would have to be carried out at another point in time (when the PCs are up and running again). Turning off or reducing the operation of the vending machine that allows customer to return used bottles would be an inconvenience to customers with bottles to return.

In terms of the store systems shutting down the ventilation does not have a large impact on the customers as temperature changes are very minor and given the store size fresh air would be available in large quantities. For the refrigeration this should also not be noticeable to employees or customers. However, we observed that employees are restocking the store in the morning and thus this disturbs the steady operation of the refrigeration units. This process adds additional consumption that could be an issue for the pre-cooling strategy, affecting the required capacity. Also in the afternoon we can see from sales and customer numbers that in this period the customers are buying a high number of products which also means opening of refrigerated units and that cooled down mass is removed. Such effects remain unexplored also by previous work by Vinther et al. (2016).

\section{Conclusion}

We have presented a detailed simulation model of a supermarket and detailed the elements of the model. We have evaluated different flexibility scenarios with the constructed simulation model by changing parameters and model elements. The results highlight options for flexibility for up to $48 \mathrm{~kW}$ is possible in the morning and a bit lower in the afternoon. Based on our ethnographic study of the work processes, we have discussed the flexibility results in light of the store operation. The conclusion is that the mentioned flexibility will impact work processes and store operation which has to be addressed to implement the flexibility options in practice. Another implementation issue is the upgrading of the store automation for operating flexibility as addressed by Hviid et al. (2019).

\section{Acknowledgment}

This work is supported by EUDP for the project FlexReStore (12413)

\section{References}

Blomberg, J., M. Burrell, and G. Guest (2003). The human-computer interaction handbook. Chapter An Ethnographic Approach to Design, pp. 964986. L. Erlbaum Associates Inc.

Hviid, J., A. Johansen, F. C. Sangogboye, and M. B. Kjærgaard (2019). Enabling auto-configuring building services: The road to affordable portable applications for smart grid integration. In Proceedings of the Tenth ACM International Conference on Future Energy Systems (E-Energy). ACM.

Hviid, J. and M. B. Kjærgaard (2018). The retail store as a smart grid ready building: Current practice and future potentials. In 2018 IEEE Power 8 Energy Society Innovative Smart Grid Technologies Conference, ISGT 2018, pp. 1-5.

Marszal, A., J. Stoustrup, J. Widén, and J. Le Dréau (2017). Simple flexibility factor to facilitate the design of energy-flex-buildings. In Proceedings of the 15th IBPSA Conference San Francisco, CA, USA, Aug. 7-9, 2017, pp. 503-510. IBPSA.

Mylona, Z., M. Kolokotroni, and S. A. Tassou (2017). Frozen food retail: Measuring and modelling energy use and space environmental systems in an operational supermarket. Energy and Buildings 144, $129-143$.

Nellemann, P., M. B. Kjærgaard, E. Holmegaard, K. Arendt, A. Johansen, F. C. Sangogboye, and B. N. Jørgensen (2017). Demand response with model predictive comfort compliance in an office building. In 8th IEEE International Conference on Smart Grid Communications. IEEE.

Piette, M. A., S. Kiliccote, and G. Ghatikar (2014). Field experience with and potential for multi-time scale grid transactions from responsive commercial buildings. In ACEEE Summer Study on Energy Efficency in Buildings.

Shafiei, S., H. Rasmussen, and J. Stoustrup (2013, Feb). Modeling supermarket refrigeration systems for demand-side management. Energies 6(2), 900920 .

Spradley, J. P. (1980). Participant Observation. Waveland Press. 
Vinther, K., T. Green, E. Shafiei, L. C. Totu, R. Izadi-Zamanabadi, and T. G. Hovgaard (2016, Sep.). Control strategies and challenges for utilizing supermarket refrigeration systems in a smart energy context. In 2016 IEEE Conference on Control Applications (CCA), pp. 593-598. 